\title{
Crop Diversification and Income Inequality in Irrigation Systems: The Case of Minipe
}

\author{
B.A.P. Kumari, S. Thiruchelvam ${ }^{1}$, H.M.H. Dissanayake ${ }^{2}$ and T. Lasantha ${ }^{3}$ \\ Postgraduate Institute of Agriculture \\ University of Peradeniya \\ Peradeniya, Sri Lanka
}

\begin{abstract}
Crop diversification leads to reduction of water scarcity problems and income inequality in irrigation systems. Irrigated areas have been witnessing a slow diversification from paddy to other field crops (OFC) during yala season. It is noted that other than descriptive comparison of the diversification potential in irrigation systems, no research effort has been made to compare agricultural economic variables. In this context, present study examines the determinants of crop diversification from paddy to OFC and explores income inequality in the Minipe major irrigation scheme. Data were collected from 90 farm-households selected from Stage I (head end - H) and IV (tail end - T) of the scheme using stratified random sampling method during April and May 2009. Comparative analysis and the binomial logit model were employed.
\end{abstract}

The study revealed that OFCs have comparative advantage over paddy for the land that does not get adequate irrigation water for paddy cultivation in yala season. The logit analysis reveals that farmers in responding to crop diversification opportunities are constrained by the inactive farmer organization (FO), markets, and poor irrigation infrastructure. This analysis also showed that the probability of the diversification was determined by family labour, FOs' collective action including irrigation management and market arrangement. Gini coefficient $(G C)$ estimations showed that there is relatively lower income inequity (GC 0.34) in Stage I compared to Stage IV (0.41). A significant proportion (27\%) of total income was derived from non farm activities in stage IV, whereas it was only $10 \%$ in the case of stage I. The farmers in Stage IV are keen and prepared for crop diversification. Therefore, enhancement of FO capacity in water management and market-oriented production in the irrigation system is important.

\section{INTRODUCTION}

During the 1980s, several Southeast Asian countries enthusiastically embraced agricultural diversification and rural industrialization as a strategy for rural development. This was partly in response to structural changes accompanying the long-term contraction of agriculture in the economy. Agricultural diversification was seen as a desirable response to these supply and demand changes and was explicitly incorporated into many countries' agricultural policy

\footnotetext{
1 Department of Agricultural Economics and Business Management, Faculty of Agriculture, University of Peradeniya, Peradeniya, Sri Lanka

2 Residential Project Manager, Agriculture Settlement Scheme, Morayaya, Minipe

3 Divisional Irrigation Engineer, Minipe Division, Hasalaka
} 
and rural development strategy (FAO, 1990). Agricultural diversification in Sri Lanka was slowly picking up momentum in favor of high-value food commodities primarily to augment income rather than the traditional concept of risk management. The nature of diversification differs across regions due to existence of wide heterogeneity in agro-climatic and socioeconomic environments (IWMI, 1996). Moreover, links between agricultural diversification and agro based industries is highlighted by the present agricultural strategy. On the other hand, successful diversification requires a commercialized agricultural system, adequate infrastructure development, and well functioning rural institutions all conditions barely present in many of the irrigation systems in Sri Lanka (DOA, 2000).

From a narrow point of view, agricultural diversification implies increasing the variety of agricultural commodities produced at the farm level. From this broader view, agricultural diversification entails more than merely growing crops other than paddy. It involves the entire rural economy and entails broadening the income sources of rural households. Farm households diversify their income sources for at least two motives. The first motive being termed as the pull factor in literature is diversification undertaken for profit motives; and the second factor termed as push factors is diversification undertaken to reduce risk in water scarcity and price shocks or respond to diminishing returns in factor use. The two motives of diversification have different implications for income and asset accumulation and inequality ${ }^{4}$ in rural areas. Inequality of economic conditions of settler farmers has been identified in many irrigation systems in Sri Lanka (Hemaratne et al., 1991). The income inequality is a prime concern of most policy makers. Reardon et al. (2000) showed that diversification strategies for the rich, usually initiated by pull factors, tend to be in many cases different from diversification strategies of the poor usually motivated by push factors in that the nonfarm income share is much larger for rich than for poor rural. Haggblade et al., (2005) reported that non-farm earnings account for 30 to $45 \%$ of rural household income across the developing world, and where available, evidence suggests that the non-farm share in rural income is increasing over time.

Farm household diversification into non-farm activities emerges naturally from diminishing or time-varying returns to labour or land, from market failures and lack of credit (Barrett et al. 2001). In this context farmer organization (FO) can play a positive role in improving crop diversification and reduce income inequality. However, in the absence of active participation of its members, the level of trust and cohesiveness can lead to distributional consequences that are inequitable. There are a number of empirical evidences on the importance of FO as social capital in affecting household welfare. Grootaert and Narayana (2001) have shown that the returns to household investment in social capital such as FO enhancement are generally greater for the poor than for the rich and greater for households with little land than for those with more land.

In Sri Lanka, government policies have onstantly emphasized paddy production as necessary drive to become more-self-sufficient in basic foodstuff. Since 1980, however, non-paddy crops, also known as other field crops (OFC) or subsidiary field crops have begun to assume greater importance in government polices. There are number of reasons for encouraging the cultivation of OFC, especially in the dry zone irrigation systems like Minipe major irrigation schemes like Mahaweli System H. However, there had been a big gap between target and

\footnotetext{
${ }^{4}$ Equality divides up common resources in a set of equal shares that can be related directly measurable parameter. Equity is based on a principle of fairness that is accepted by all members of the community involved in sharing a common resource. In practice large irrigation systems are almost and always based on water entitlement on equality rather than equity because of the difficulty in determining what society considers fair.
} 
achievement of OFCs cultivation in such schemes. An early study conducted in the Mahaweli System H, (Deegan and Herath, 1980) identified three categories namely physical, organizational and socio cultural aspects operative in farmers' decision about growing OFCs. The statistics suggest that OFC cultivation progress over time was very slow (CBR, 2008). This is more pronounced in marginalized areas like the Minipe major irrigation scheme.

Given the importance of crop diversification potential in rural areas of developing countries, the central question regarding the crop diversification economy then revolves around causal dynamics - whether and under what conditions crop diversification increases or decreases overall rural inequality. The diversification of agriculture towards non-food grain and high value commodities has been the right answer for it, because these commodities have potential of income augmentation, employment generation, poverty alleviation and export promotion (Barrett et al., 2001; Haggblade et al., 2005 and Reardon et al., 2000). To support the diversification policy, understanding of determinants of the diversification is necessary. The issues related to crop diversification in paddy lands are multifaceted (IWMI, 1996). Despite the frequent observations that diversification plays an important role in agriculture, there are only a few empirical studies on the factors that affect diversification.

The main objective of this study is to examine the determinants of crop diversification from paddy to other field crops (OFC) and explores income inequality in the Minipe major irrigation scheme. Specific objectives of the study are:

1. To examine the comparative advantage of OFC over paddy cultivation in Stage I and Stages IV of the Minipe irrigation scheme.

2. To investigate the determinants of crop diversification in Stage I and Stage IV of the Minipe irrigation scheme.

3. To examine income distribution among farmers in Stage I and Stages IV of the Minipe irrigation scheme.

\section{METHODOLOGY}

Minipe scheme is one of the largest anicut schemes in Sri Lanka which was originally built in the fifth century. It is located in lower Mahaweli basin occupying the area between eastern foot hills of Knuckels range and the left bank of Mahaweli river. Minipe scheme is irrigated by Minipe Yoda Ela (Main canal) flowing parallel to the Mahaweli spread like a belt over 74 $\mathrm{km}$ length towards the North and the South. Minipe scheme can be divided into two major agro climatic areas. The Stages I and II belong to Kandy district. Minipe Stage III and IV belong to Matale district. Rain fall ranged between 1,513 and 1,132 $\mathrm{mm}$ per annum in the first two and the last two stages, respectively. Irrigation canal is designed for the distribution of water among 5,200 farm units serving over 6,107 ha to 12,000 farm families spread over an area of about 400 sq. km. Eight minor tanks served as storage tanks for 967.3 ha. Soil types are reddish brown and low humic glay having high and medium infiltration in I, II and IV stages and suitable for OFCs cultivation (Land Commissioner Department, Mahiyangana, 2008). The Minipe anicut irrigation scheme was selected for this study because of the failure of the attempt made by the project management in linking farmers with Plenty Food Ltd and Golden Grain for contract and OFCs cultivation. The officials are unable to find the root cause for farmers not following OFCs cultivation. 


\section{Sampling and data collection}

A two stage sampling design was used in this study to make representative samples of the two different agro-ecological zones of the project. The primary sampling units were distributary canals. The stratification of farms was based firstly on the location of the farm in the irrigation systems with respect to water distribution and channel network. Second sampling unit canals were selected on the basis of secondary information collected from the project. The study population considered were 428 and 456 farm families in the Stages I and IV respectively. Finally, a random sample of 45 farmers from each in Stage I (head reach) and Stage IV (tail reach) were selected.

Field survey, focus group discussion (FGD) and key informant interviews were conducted during April and May 2009. FGD was used to elicit the common understanding of people about the issues being researched. A pre-tested questionnaire schedule was used to gather information on household income, expenditure, off-farm income, household assets, agricultural variables, collective efforts of farmer organization, and other information related to production and sales. To obtain data on the reasons why farmers were not growing OFCs; an open ended question format was adopted. Farmers were asked to rank the important reasons as to why they did not grow OFCs during yala 2008. Necessary secondary information was collected from Irrigation Department, Minipe Project Management, Department of Agriculture and Department of Agrarian Service.

\section{Analytical method}

The empirical analysis of this research relied on testing the following two main hypotheses

1. There are no reasons for farmers not to adopt OFC cultivation during yala.

2. Adoption of $\mathrm{OFC}$ cultivation has no effect on income inequality among the farmers.

To achieve the above objectives initially, descriptive statistics were used to present the characteristics of farmers, their resource use pattern and described the general situation of the crop diversification. Comparative analyses were made to show the difference in the above characteristics of farmers, yala paddy and OFC cultivation between Stage I and Stage IV in the Minipe scheme.

Inequity of income distribution among the farmers in the sample of Stage I and Stage IV was measured by the Gini Coefficient. Income obtained from different sources, each of which can have its own contribution to the level of inequality was also analyzed.

\section{Crop diversification decision and hypothesis}

Farm diversification was measured by using Entropy index (Pope and Prescott, 1980). An Entropy measure of farm diversification considers the number of enterprises a farm participates in and relative importance of each enterprise to the farm. The Entropy index spans a continuous range from 0 to 1 . The value of index for a completely specialized farm producing one crop is 0 . A completely diversified farm with equal shares of each crop has an entropy index of 1 . The minimum and maximum computed values of entropy index were 0 and 0.21 , respectively.

The values of crop diversification index computed for measuring horizontal diversification were taken as dependent variable and different factors affecting diversification were taken as independent variables. The model is applied to all households in the sample. Using Ordinary 
Least Squares (OLS) to estimate the model to all households, where many households do not follow OFC diversification and have zero values, would lead to biased and inconsistent results. Hence Logit regression was used to estimate the model. Thus, instead of crop diversity index farmers interest ( $\mathrm{Yes}=1$ or No $=0$ ) on $\mathrm{OFC}$ cultivation during yala considered as dependent variable to analyze the factors determinants crop diversification. The model is based on the cumulative logistic probability function,

$$
\mathrm{Pi}=1 /\left(1+\mathrm{e}\left(\alpha+\beta_{\mathrm{i}} \mathrm{X}_{\mathrm{i}}\right)\right)
$$

When (1) $\mathrm{Pi}=$ probability that an individual will make a certain choice, (2) e is base of natural logarithm, (3) Xi = explanatory variables, (4) $\alpha$ and $\mathrm{Bi}=$ constant and coefficient of $\mathrm{Xi}$. The function can be transformed to

$$
\mathrm{Li}=\log (\mathrm{Pi} /(1-\mathrm{Pi}))=\alpha+\beta \mathrm{i} \mathrm{Xi} \text { which will be used in the estimation. }
$$

The dependent variable in this model is $\mathrm{Li}$ or $\log (\mathrm{P} / 1-\mathrm{Pi})$ of which $\mathrm{Pi}$ is the probability that each farmer will diversify his paddy land to other field crops. On the other hand, a set of variables including farmer characteristics, farm resource endowments, and infrastructural conditions are expected to be the determinants of the diversification.

The key dependent variables were interest in diversification, number of activities taken to learn about diversification and perceived barriers to crop diversification. These outcomes were analyzed with logistic regression for binary dependent variables. Interest in crop diversification was assessed with the question: "In general, are you interested or uninterested in trying crop diversification during yala farm activities to supplement your paddy income?" Those responding either "somewhat interested" or "very interested" were considered to have a "yes" response whereas those responding "somewhat uninterested" or "very uninterested" were considered to have a "no" response.

Factors influencing farmers' crop diversification decision are broadly categorized into personal factors, economic factors, institutional factors and physical factors. The determinants of factors influencing OFC cultivation and their expected relationships are shown in Table 1. In view of postulate that young and educated farmers accept new things and adopt crop diversification earlier than older and less educated farmers. Experience in OFCs cultivation in small extent may know how to reduce risk and more confidence in diversifying paddy to OFC cultivation. Therefore, a positive relation between crop diversification and experience in OFC cultivation is assumed. Different categories of farmers such as full time and part time can influence crop diversification differently. It is expected that full time farmers are more involved in OFCs cultivation. Since OFCs cultivation needs more intensive care than paddy, the positive relation between family labour availability is expected.

In economic factors, land extent available to grow OFCs is expected to have a positive relation with diversification. Debt level (ID) (Scale crop loan due in the last season is categorized into $>$ Rs. 5,000 high $=3$; Rs.5, $000<>2,500$ medium $=2 ;<$ Rs. 2,500 Low $=1$ ): Due to higher capital required for OFCs cultivation, income is strongly believed to be an important determinant of crop diversification. Thus, an anticipated reaction in higher debt is not to adopt crop diversification. Since marketing experience provides farmers with a business sense and wider view point, it is likely that they become more exposed to the idea of crop diversification. Therefore, the positive relation between the experience and diversification to OFC is expected. In this paper, the experience is represented by a dummy variable, whose value is 1 and if farmer had experience with contract or market oriented production it is 0 . 
In institutional factors, collective effort of farmers in FO activities is calculated as scale frequency in participation in meetings into 3 levels, high (all the meetings), medium (important meeting), and low (not participated), which represented contribution to FO decision making more frequently, less frequently and not contributed. Then 3,2 and 1 points were assigned for high, medium and low respectively. The average score of each farmer was calculated and assigned as FO membership level in the analysis.

Table 1. Expected relationships of selected variables and OFC s cultivation

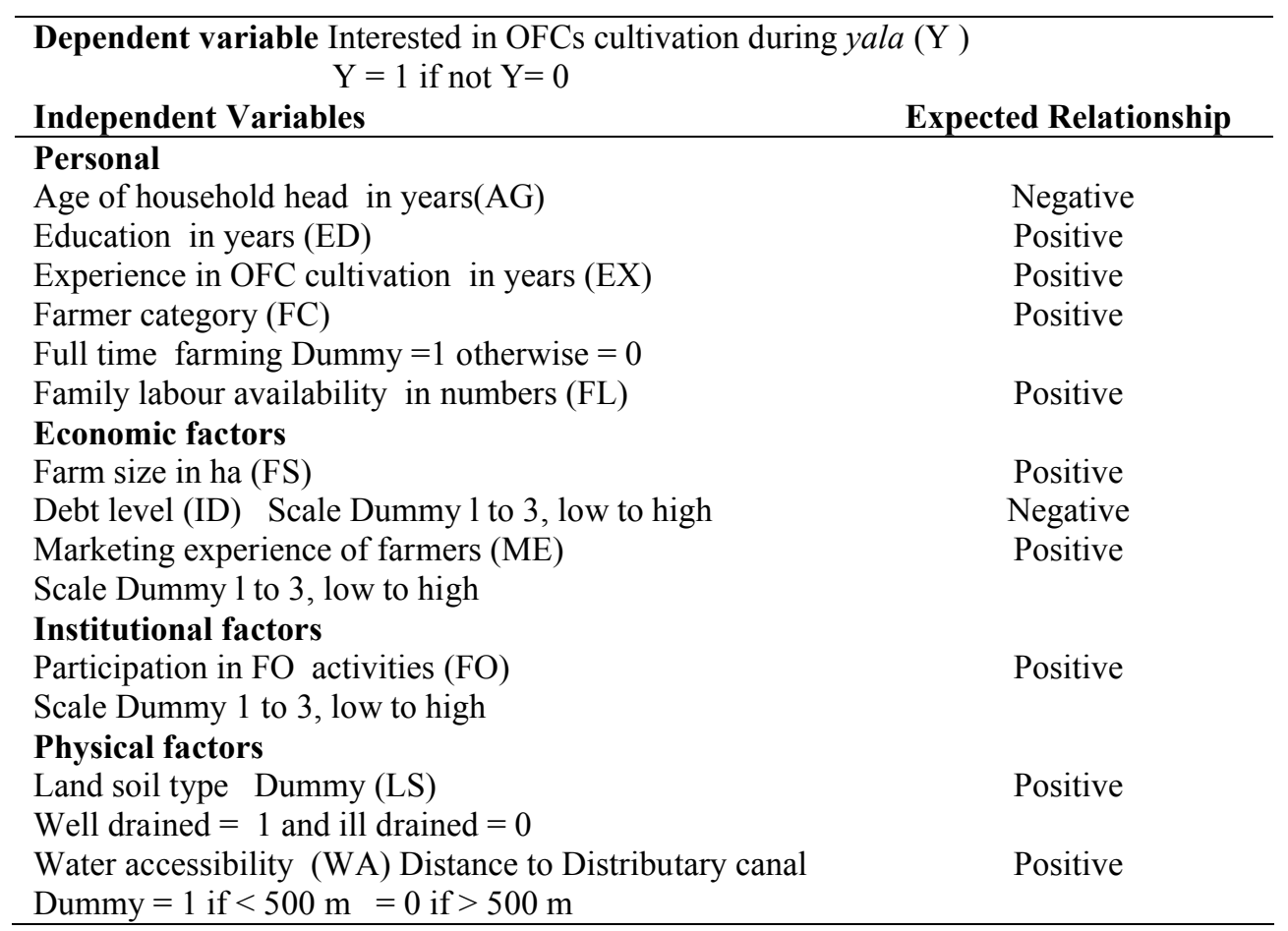

Collective action in farmer organization, is likely to get more easily exposed to the idea of crop diversification. Farm Organizations can enhance crop diversification through more support and providing information regarding crop diversification. Therefore, the positive relation between participation in FOs activities and crop diversification is expected. In physical factors, well drained soil type and reliable irrigation are important for crop diversification. High, medium and less categories of drainage were assigned 3, 2 and 1 points, respectively. Well drained soil and access to reliable irrigation are expected to have a positive relation with the diversification to OFCs. As a proxy for head and tail end, water accessibility distance from distributary canal was considered. It was hypothesized that for lands closer to distributary canal (less than $500 \mathrm{~m}$ ) water accessibility is more reliable and encourage crop diversification than lands further from distrbutary canal.

The empirical model is specified as follows:

$\log (\mathrm{Pi} /(1-\mathrm{Pi}))=\alpha+\beta_{1} \mathrm{AG}+\beta_{2} \mathrm{ED}+\beta_{3} \mathrm{EX}+\beta_{4} \mathrm{FC}+\beta_{5} \mathrm{FL}+\beta_{6} \mathrm{FS}+\beta_{7} \mathrm{ID}+\beta_{8} \mathrm{ME}+$ $\beta_{9} \mathrm{FO}+\beta_{10} \mathrm{LS}+\beta_{11} \mathrm{WA}+\varepsilon$ 
To get a clear picture, the model was run for Stage I and Stage IV separately and pool data analysis was also carried to find the collective action of farmers in FOs on adopting OFCs cultivation. STATA software was used to run the models.

\section{RESULTS AND DISCUSSION}

\section{Farmers' characteristics}

Table 2 presents summary data for the farmers' household characteristics and their various sources of income. It was found that the average age of the farmers in the Stage I and Stage IV were 47 and 50 years, respectively. Farming experiences ranged between 28 to 30 years. Average schooling years was 10 and 7 in Stages I and IV, respectively. Nearly $70 \%$ of the sample population was engaged in full time farming and about $90 \%$ of the sample was involved in paddy cultivation in both stages, with mixed adoption of OFCs which is higher $(22.2 \%)$ in Stage I than Stage IV (11.6\%).

The average family size for Stage I and Stage IV were 6 and 5 respectively. Economically active population was above $65 \%$ in both stages. The average holding size is significantly larger,1.07 and 0.77 ha, in Stage I compared to stage IV, 0.61 and 0.52 ha of high land and low land, respectively.

Table 2. General characteristics of the head of farm household in Stages I \& IV Minipe Scheme

\begin{tabular}{|c|c|c|c|}
\hline Items & $\begin{array}{l}\text { Stage I }(\mathrm{H}) \\
\mathrm{n}_{1}=45\end{array}$ & $\begin{array}{c}\text { Stage IV (T) } \\
\mathrm{n}_{2}=45\end{array}$ & $\mathrm{~T}-$ test \\
\hline Average age (yrs) & 47 & 50 & 0.854 \\
\hline Average education (yrs) & 11 & 07 & $1.452 *$ \\
\hline Family size (persons) & 06 & 05 & 0.721 \\
\hline Family labour availability (no) & 3.2 & 2.4 & $1.567^{*}$ \\
\hline Holding size (ha) High land & 1.07 & 0.61 & $2.121 * * *$ \\
\hline Low land & 0.77 & 0.52 & $1.455^{*}$ \\
\hline Full time farmers $(\%)$ & 71 & 73 & 0.121 \\
\hline Tenant farmers $(\%)$ & 39 & 27 & 1.267 \\
\hline Farmers cultivating OFC (\%) & 22.3 & 11.1 & $2.231 * * *$ \\
\hline Livestock raised $(\%)$ & 14 & 25 & $2.151 * * *$ \\
\hline Average family income Rs./month & $21,900(5,165)$ & $5,130(7,954)$ & $2.273 * * *$ \\
\hline Crop production Income (\%) & 69 & 59 & $1.356^{*}$ \\
\hline Livestock income contribution (\%) & 12 & 14 & 1,125 \\
\hline Non farm income contribution (\%) & 10 & 27 & $2.471 * *$ \\
\hline Farmers earning $<$ Rs.3,500/mn $(\%)$ & 18 & 31 & $1.719^{*}$ \\
\hline Gini coefficient & 0.34 & 0.41 & $1.478 *$ \\
\hline Farmers cultivating OFCs (\%) & 22.2 & 11.6 & $1.562 * *$ \\
\hline Cropping intensity & 1.99 & 1.52 & $2.181 * * *$ \\
\hline
\end{tabular}

Source: Survey 2009, Note: figures in parenthesis are the standard deviations and $*, * * *, * * * *$ significant at $0.10,0.05$ and 0.01 levels, respectively. 


\section{Rural income inequality}

The average monthly family income of sample population was significantly different between Stage I and Stage II as Rs. 21,900 and 15,130 respectively. Source of Income was divided into three sources as (a) non-farm - the non-farm income includes wage employment, Samurdhi transfers, income from own business etc. (b) Agricultural Income (Crop Income) - this includes all income from crop production both during maha and yala. (c) Livestock - this includes income from the sale of animals and animal products.

As an agricultural society, crop production constitutes a larger share of income source. Table 2 shows that a larger share of the income source comes from crop production contributing $69 \%$ and $59 \%$ of the total income in Stages I and IV, respectively. This is followed by nonfarm contribution, where Stage IV had higher share (27\%) compared to stage I (10\%). However, in the study area off-farm activities were less dependable income source, suggesting that the yala season crop diversification will be an essential part of viable and sustainable farming system. Livestock income contributes to the remaining 12 and $14 \%$ which was almost similar to shares of the income for the Stage I and Stage IV farmer groups, respectively.

The study finds significant inequity in water distribution across head (Stage I) and tail (Stage IV) reaches of the scheme. Inequity in water distribution exists even if there is less inequality in land distribution. Inequality in water distribution translates into productivity differences, with lower productivity downstream, where paddy productivity varied from 4.86 to $4.3 \mathrm{mt} / \mathrm{ha}$ at the head to $3.46-4.16 \mathrm{mt} / \mathrm{ha}$ at the tail. The larger farm size coupled with higher cropping intensity has resulted in higher income in Stage I compared to Stage IV. The study further found that, as a result of less access to water and lower productivity, poverty incidence at tail ends is higher than at head and middle reaches. The problem of tail reach poverty exists mostly where there are neither alternative water sources nor alternative sources of employment (nonagricultural enterprises). Income inequity incidence increases with reduced irrigation water access (tail ends) which was worse in low, yala season harvests. Income distribution in Stage I was low Gini coefficient of (GC) 0.34 and comparatively higher inequity GC 0.41 existed in the Stage IV irrigation system. Gini coefficients are less than Sri Lanka's GC value of 0.44 . The main reasons for higher inequality in stage IV compared to Stage I may be due to small and fragmented land and inadequate irrigation water. About 18 and $31 \%$ of the farmers accounted for the poor in Stages I and IV, respectively. These findings of this study are consistent with the findings of Hemaratne, et al., in 1991 and support the hypothesis that command areas of specific canal reaches receiving less irrigation water per ha have lower productivity and a higher incidence of income inequality.

\section{Comparison of cost and returns in paddy and OFCs during yala}

Comparative mean analysis of input costs and yield in paddy and other field crop production during 2008 yala in Stages I and IV are given Table 3. Although diversification of cropping pattern to include OFCs had not occurred yet in the sample areas, to any appreciable degree, some respondents reported the use of highland allotment for OFC cultivation. For the crop year yala 2008, the sample farmers in both stages had adhered to mono cropping pattern where a maha paddy crop is followed in yala by a paddy crop again. Cropping intensities were 0.99 and 0.51, respectively in Stages I and IV in the Minipe scheme. Farmers in Stage I had sufficient irrigation water in both season and due to higher net income, paddy cultivation is followed and there is less potential for crop diversification. Even though, crop 
diversification is more advantageous in Stage IV, due to insufficient irrigation water for paddy cultivation during yala, farmers continue to show less interest in cultivating OFCs.

Table 3. Costs and Returns (Rs. /ha) in OFC cultivation in Minipe scheme during Yala 2008

\begin{tabular}{|c|c|c|c|c|c|c|}
\hline \multirow[t]{2}{*}{ Item } & \multicolumn{2}{|c|}{ Paddy } & \multicolumn{2}{|c|}{ Maize } & \multicolumn{2}{|c|}{ Soybean } \\
\hline & Stage I & Stage IV & Stage I & Stage IV & Stage I & Stage IV \\
\hline Cultivated & 1.0 & 0.3 & 0.4 & 0.1 & 0.2 & 0.05 \\
\hline $\begin{array}{l}\text { Extent. ha. } \\
\text { Yield t/ha }\end{array}$ & $4.53 \mathrm{a}(13)$ & 3.93 & $2.20 \mathrm{a}(3)$ & $1.87 \mathrm{~b}$ & $1.68 \mathrm{a}(7)$ & $1.57 \mathrm{~b}$ \\
\hline $\begin{array}{l}\text { Gross Income } \\
\text { Rs/ha }\end{array}$ & 126,849 a (13) & $110,040 \mathrm{~b}$ & 70,400 a (15) & $59,840 \mathrm{~b}$ & 100,800 a (7) & $94,200 \mathrm{~b}$ \\
\hline $\begin{array}{l}\text { Gross Cost } \\
\text { Rs/ha }\end{array}$ & 51,972 a $(-8)$ & $56,023 \mathrm{~b}$ & 30,288 a $(-3.3)$ & $31,287 \mathrm{a}$ & 37,706 a $(-3)$ & $38,710 \mathrm{a}$ \\
\hline $\begin{array}{l}\text { Net Income } \\
\text { Rs/ha }\end{array}$ & 74,868 a (27.9) & $54,017 \quad b$ & 40,112 a (28.8) & $28,553 \mathrm{~b}$ & $63,094 \mathrm{a}(12.5)$ & $55,490 \mathrm{~b}$ \\
\hline
\end{tabular}

Profit from paddy was estimated to be Rs.74,868 and 54,017 per hectare for Stage I and Stage IV respectively, at the rate of Rs $28 / \mathrm{kg}$ to paddy during 2008 yala. Among cereal crops, maize was picking up fast in the major irrigation schemes, and to some extent in the minor tanks also, largely for human consumption and as poultry feed. The higher prices received for maize and soybean of Rs. 32 and 75-80 per $\mathrm{kg}$ respectively and due to comparatively low cost of production, the profit earned from OFCs ranged between Rs. 28,553 and $63,940 /$ ha. These results indicated that there is a comparative advantage for OFC diversification when the land does not get reliable irrigation that leads to increase in cost and decrease in yield in paddy cultivation in yala season. Stage IV had comparatively higher cost $(7 \%)$ and low yield (13\%) than Stage I. This situation revealed that the income increase in Stage IV can be achieved by adopting good agricultural practices rather than increase of inputs.

During yala, farmers response to OFC choice could be expected as cost of production is about $25 \%$ less than paddy. OFCs cultivation during yala season is an effective way of increasing agricultural productivity and income. Crops which require less water (less than 3 ac $\mathrm{ft}$ ) compared to paddy (use $6 \mathrm{ac} \mathrm{ft}$ ) such as maize, soybean and cowpea can be successfully grown in marginal lands with less irrigation requirement. Above analysis highlighted that there is a comparative advantage for the land that does not get adequate irrigation for paddy cultivation in yala season for OFC diversification.

\section{Determination of diversification to Other Field Crops}

Heteroscedasticity arising due to cross-sectional data was corrected by using Goldfeld and Quant test. Multicollinearity was tested using the correlation matrix of the independent variables and it was found that farm size was highly correlated with farming category. Thus, farm size was dropped from the model in order to avoid multicollinearity. Age and experience in OFC cultivation were correlated to some extent (0.56). Land drainage conditions and water accessibility measured in terms of distance from distributary canal also showed a correlation coefficient of 0.63 . These results indicate that there were slight multicollinearity problems and dropping theses variables did not improve the results. 
The estimation of two diversification models for Stages I and IV are presented in Table 4. In both models the explanatory variables farming experience, farmer organization and marketing experience were significant as expected. In addition, land suitability and full time farming showed an impact in Stage I. Chi-square statistics indicated that the models were significant at $10 \%$ level.

The coefficient of age is negative and non significant. It means that older farmers are less likely to diversify as compared to young farmers. This result is also consistent with the findings of other studies (Mishra and El-Osta, 2002). The reason is that older farmers cannot manage the farms properly and usually stick with old farming practices. The main variables that affect both stages were farming experience (FE), market experience (MK), and farmer organization (FO). Among these, FO has a highly significant positive coefficient, suggesting that farmers obtained better service from FO and higher probability diversification to OFCs. It was found that FOs in Stage IV were generally efficient compared to FOs in Stage I. Farmer Organizations in Stage I were active and had more meetings, better coordination with government officers and had more funds. Due to less water, they cultivated 3 to $3 \frac{1}{2}$ months varieties, harvested early and received higher price for their paddy (Rs. 30/kg) than the Stage I FOs who cultivated 4 month varities and harvested late These indicate that the growing scarcity and rising value of water in a basin induces both farmers and FOs to seek various ways to increase water productivity, economic efficiency and net returns. A more recent study (Thiruchelvam and Lasantha, 2009) finds that there is considerable scope to increase economic productivity of both land and water in Minipe scheme through crop diversification and value addition to farm produce.

Table 4. Logit regression analysis of factors affecting the probability of OFC diversification during Yala 2008 - Minipe anicut scheme

\begin{tabular}{|c|c|c|c|c|c|c|c|}
\hline \multirow{2}{*}{\multicolumn{2}{|c|}{ Variable }} & \multicolumn{3}{|c|}{ Stage I } & \multicolumn{3}{|c|}{ Stage IV } \\
\hline & & Coeffi & Std. Err & $\mathrm{P}>/ \mathrm{z} /$ & Coeffi & Std. Err & $\mathrm{P}>/ \mathrm{z} /$ \\
\hline Constant & & -4.451 & 1.320 & 0 & -3.173 & 1.521 & 0 \\
\hline Age & $\mathrm{AG}$ & -0.034 & 0.721 & 0.951 & -0.017 & 0.953 & 0.641 \\
\hline Education & ED & 0.151 & 0.236 & 0.631 & 0.643 & 0.514 & 0.424 \\
\hline Experience & e EX & $0.114^{*}$ & 0.012 & 0 & $0.251 * *$ & 0.103 & 0 \\
\hline Farming & $\mathrm{FC}$ & 0.813 & 0.451 & 0.362 & $-0.606^{*}$ & 0.171 & 0.024 \\
\hline Labour & FL & $0.271 *$ & 0.015 & 0.021 & $0.916 * *$ & 0.051 & 0.001 \\
\hline Farm Size & FS & 0.104 & 0.062 & 0.310 & 0.605 & 0.430 & 0.318 \\
\hline Debt & ID & 0.174 & 0.152 & 0.731 & 0.035 & 0.679 & 0.346 \\
\hline Market & $\mathrm{ME}$ & $0.129 * *$ & 0.033 & 0.005 & $0.136 * *$ & 0.011 & 0.014 \\
\hline Member & FO & $2.017 * *$ & 0.274 & 0 & $1.831 * *$ & 0.063 & 0 \\
\hline Land & LS & 0.784 & 0.641 & 0.704 & 1.925 & 0.340 & 0.176 \\
\hline Water & WA & 0.326 & 0.207 & 0.309 & -0.515 & 0.340 & 0.421 \\
\hline \multicolumn{4}{|c|}{ Number of observations } & 45 & & & 45 \\
\hline \multicolumn{4}{|c|}{ LR chi $^{2}$} & $12.45 * *$ & & & $18.01 * *$ \\
\hline \multicolumn{4}{|c|}{ Porb $>$ chi $^{2}$} & 0 & & & 0 \\
\hline \multicolumn{4}{|c|}{ Log likelihood } & -52.04 & & & -48.95 \\
\hline \multicolumn{2}{|c|}{ Pseudo $\mathrm{R}^{2}$} & & & 0.148 & & & 0.164 \\
\hline
\end{tabular}


Education is not statistically significant in both stages of the scheme. But coefficient of farming experience of the farmers is positively and significantly related to crop diversification. It means that experienced farmers are more likely to diversify as compared to less experienced farmers. Family labour is statistically significant in both stages, indicating more labour requirement for OFC cultivation and needs more intensive care than for rice. Debt level was not found to be significant indicating the cost of production of OFC cultivation was low compared to paddy cultivation. Full time farming had significant negative effect on OFC cultivation in Stage IV. Large extent of cultivation (1.7 ha) and higher income from paddy compared to OFC cultivation may be the reasons for non significance in Stage I. It is important to note that land suitability (LS) and water accessiblity (WA) are not significant factors in both stages. The reason needs to be explored. WA had the expected negative relationship in Stage IV indicating that it did limit OFC cultivation compared to Stage I. Other ancillary reasons for farmers' reluctance to cultivate OFCs included market, price risk, information and effectiveness of FO.

Table 5 indicates that, at the mean of land available for OFC ( $0.25 \mathrm{ha})$, cost of cultivation (Rs.38,710/ha) and family labour availability $(2.5 \mathrm{md})$, for pooled data model, when the level of FO active level increases from low to good level, the probability of diversification of land use by farmers increased from -0.119 to 1.079 . This analysis points out the importance of improving the management ability of FO in the probability of crop diversification. This finding agrees with the assessment from the focus group discussions that comparatively Stages IV had more collective action in their FOs than Stage I. A strong linkage amongst production, marketing and processing is a primary requirement for the promotion of highvalue commodities. The markets for these food commodities were thin, fragmented and lack basic facilities. Appropriate institutional arrangements in the form of contract farming with FOs can integrate production with markets.

Table 5. Probability of diversification to OFCs and Farmer Organization performance, Minipe Scheme

\begin{tabular}{lcc}
\hline FO Collective action & Logit & Pi \\
\hline Low & -0.119 & 0.233 \\
Medium & 0.057 & 0.435 \\
Good & 1.079 & 0.672 \\
\hline Source: Calculated from pooled data of 90 observations in logit model. \\
\multicolumn{2}{l}{ Pi : probability of crop diversification. }
\end{tabular}

Literature showed that innovative institutional arrangements can effectively link production and markets and improve the marketing efficiency (Birthal et al., 2005). Thus, enhancement of FOs capacity in operation and management of irrigation system below distributary canals and market oriented production are important on order to benefit more from the diversification effort shown by the farmers in the irrigation scheme.

\section{CONCLUSIONS}

This study was carried out to examine the determinants of crop diversification from paddy to other field crops (OFC) and explore income inequality in the Minipe major irrigation scheme. Analysis leads to the following major conclusions. 
The study finds significant inequity in water distribution across head (Stage I) and tail (Stage IV) reaches of Minipe scheme. Inequity in water distribution translates into productivity differences, with lower productivity at tail reaches. Inadequate irrigation for paddy cultivation and significant proportion $(27 \%)$ of non-farm income to total income were found to be the main reasons for none exploiting the potential of crop diversification in Stage IV.

Comparative mean analysis reflects that there is a comparative advantage for land that does not get adequate irrigation for paddy cultivation in yala season for OFC diversification. Education and age had no relation with crop diversification, while family labour availability, collective efforts in FO, and market experience had positive relation to OFC diversification during yala.

Since farm-level diversification is most relevant for household income and inequality, attention should be focused on increased productivity of agriculture through diversification into high-value crops. Policies should be directed to removing constraints in the production of and marketing of high-value crops.

It is recommended to project management that long-term plans be established for land use, and irrigation water supply during the yala season be stabilized. In order to promote diversification among farmers as a good tool for avoiding risks and to ensure a sustainable farm income, it is suggested that FO be promoted through capacity building in water management and market oriented production.

\section{ACKNOWLEDGMENT}

Authors wish to thank anonymous reviewers for their suggestions and creative criticisms. Thanks are also extended to the Minipe Irrigation Scheme Stage I and IV farmers and farmer organizations for their valuable cooperation extended during data collection of this study.

\section{REFERENCE}

Central Bank of Sri Lanka. (2008). Annual report, Colombo, Sri Lanka.

Barrett, C.B., Reardon, T. and Webb, P. (2001). Nonfarm income diversification and household livelihood strategies in rural Africa: Concepts, dynamics, and policy implication. Food Policy. 26(4): 315-331

Birthal, P.S., Joshi, P.K. and Gulati, A. (2005). Vertical coordination and high-value commodities: implications for smallholders. MTID. International Food Policy Research Institute, Washington, DC. (memio)

Deegan, J.I. and Herath, M.A.L.H. (1982). Farmers reluctance to grow subsidiary crops in the Mahaweli System H during Yala 1980. J. the National Agricultural Society of Ceylon. 10: $71-110$. .

Grootaert, C. and Narayan, D. (2001). Local Institutions, Poverty, and Household Welfare in Bolivia. World Bank Policy Research Working Paper No. 2644. 
Haggblade, S., Hazell, P. and Reardon, T. (2005). The rural nonfarm economy pathway out of poverty or pathway in? Available Online, linkinghub.elsevier.com/retrieve/pii/S0305750 X08003306.

Hemaratne, H., Abegunawardena, P and Thilakaratne, M.W. (1991). Income inequalities and different level of water availabilities in irrigation schemes: The Case of Minipe. Tropic. Agric. Res. 3: 290 - 302 .

International Irrigation Management Institute (IWMI), (1996). Potential for Diversified Cropping in the Rice Lands of Sri Lanka, Institutional Irrigation Management Institute (IMI) IMI Country Paper, Sri Lanka No. 14.

Jayawardane, S.S.B.D.G. and Weerasena, L.A. (2003). Crop diversification in Sri Lanka RAP publication 2001/03, Crop Diversification in the Asia -Pacific Region. Food and Agriculture Organization of the United Nations Regional Office Asia and the Pacific Bangkok, Thailand.

Mishra, A. and El-Osta, H. (2002). Risk management through enterprise diversification: A farm level analysis. Paper presented at AAEA meetings in Long Beach, CA, U.S.A.

Pope, R.D. and Prescott, R. (1980). Diversification in relation to farm size and other socioeconomic characteristics. Amer. J. Agric. Econ. 62(3): 554-559.

Reardon, T., Taylor, J.E., Stamoulis, K., Lanjouw, P. and Balisacan, A. (2000). Effects of nonfarm employment on rural income inequality in developing countries: An investment perspective. J. Agric. Econ. 51(2): 266-288.

Thiruchelvam, S. and Lasantha, T. (2009). Water as an economic good as a tool for integrated water resource management: A study of the Minipe irrigation scheme, Sri Lanka. Water Resources Res. in Sri Lanka. 7: 158- 169. 